Estudios Románicos, Volumen 29, 2020, pp. 253-267

ISSN: 0210-4911

eISSN: $1989-614 \mathrm{X}$

DOI: https://doi.org/10.6018/ER.421661

\title{
ESTABILIDADE E MUDANÇA NA ESTRUTURAÇÃO DE SEGMENTOS TÓPICOS EM CARTAS DE LEITOR: CONTRIBUIÇÃO À HISTÓRIA DO PORTUGUÊS BRASILEIRO
}

(Preservation, modification of structuring of minimum topic segments in reader's letter: contribution to the history of brazilian portuguese)

\author{
Clemilton Lopes Pinheiro* \\ Universidade Federal do Rio Grande do Norte (UFRN)
}

\begin{abstract}
In this work, we consider Eugenio Coseriu's conception about language levels and understand that a process of textual construction as such does not belong to any language (historical level), but to the individual level of texts. In these terms, a given process can be repeated, over time, in a set of texts related to a genre and be configured as a discursive tradition. In this sense, our objective is to analyze the permanences, modifications or exclusions of the internal structuring of minimum thematic segments in a set of reader's letters that constitute the corpus of the Project History of Brazilian Portuguese in Rio Grande do Norte (PHPB-RN). We have observed patterns of repetition, exclusion, and insertion which mobilize subunits of two prototypical rules of intra-topic structuring, connected to the genre's communicative purpose, which constitutes a discursive tradition. In the present case, an unstable tradition.
\end{abstract}

Keywords: Brazilian Portuguese; Discourse tradition; Discourse topic; Textual organization.

Resumo: Neste trabalho, consideramos a concepção de Eugenio Coseriu sobre os níveis de linguagem e entendemos que um processo de construção textual como tal não pertence a nenhuma língua (nível histórico), mas ao nível individual dos textos. Nesses termos, um determinado processo pode ser repetido, ao longo do tempo, em

* Dirección para correspondencia: Departamento de Letras. Centro de Ciências Humanas, Letras e Artes, Universidade Federal do Rio Grande do Norte (UFRN). Av. Senador Salgado Filho, S/n - Lagoa Nova, Natal - RN, 59078-970. (clemiltonpinheiro@hotmail.com). 
um conjunto de textos relacionados a um gênero e ser configurado como uma tradição discursiva. Nesse sentido, nosso objetivo é analisar as permanências, modificações ou exclusões da estruturação interna de segmentos tópicos mínimos em um conjunto de cartas de leitores que constituem o corpus do Projeto História do Português Brasileiro no Rio Grande do Norte (PHPB-RN). Observamos padrões de repetição, exclusão e inserção que mobilizam subunidades de duas regras prototípicas de estruturação intratópica, ligadas ao propósito comunicativo do gênero, o que constitui uma tradição discursiva. No presente caso, uma tradição instável.

Palavras-chave: Organização textual; Portugûes brasileiro; Tópico discursivo; Tradição discursiva.

\section{Introdução}

No Brasil, os estudos linguísticos históricos e diacrônicos receberam um grande impulso com o surgimento do Projeto Para a História do Português Brasileiro (PHPB), em 1997, sob coordenação geral do professor Ataliba Teixeira Castilho. O Projeto vem desenvolvendo, desde sua fundação, estudos com base nos corpora levantados, com o objetivo de conhecer e descrever a realidade linguística do português brasileiro. É um projeto nacional que agrega pesquisadores de diversas universidades e envolve equipes de diferentes estados das cinco regiões do país (Castilho e Hora 2010, Castilho 2011).

O PHPB trabalha com um banco de dados composto por dois tipos de corpora que são comuns a todas as equipes filiadas ao projeto: o corpus comum mínimo manuscritos e o corpus comum mínimo - impressos. O primeiro grupo é composto por: 1) testamentos; 2) processos-crime; 3) atas de câmara; 4) cartas particulares; 5) cartas da administração privada; 6) cartas oficiais. O segundo grupo: 1) cartas de redatores/ editoriais; 2) cartas de leitores; 3) anúncios. Além desses dois corpora, há ainda um corpus comum diferencial, composto por: 1) inventários; 2) memórias/relatos históricos e diários históricos de viagem; 3) entremezes e outros textos teatrais; 4) inquéritos orais. As análises empreendidas abarcam diferentes domínios: história social do português brasileiro, mudança fônica, mudança sintática, léxico histórico, diacronia dos processos constitutivos do texto.

Este trabalho procura atender ao propósito central do projeto Para a História do Português Brasileiro (PHPB) de conhecer e descrever a realidade linguística do português brasileiro, especificamente no que diz respeito à diacronia dos processos de construção textual. Tomamos como objeto particular de análise a estruturação dos segmentos tópicos (SegTs) mínimos, concebidos como unidades linguísticas de organização textual (Pinheiro 2005, Penhavel 2010).

Consideramos o pressuposto teórico de que a organização tópica é determinada pela situação comunicativa, e, por isso, pertence ao nível individual dos textos (Coseriu 2007). Nesse sentido, uma dada regra de estruturação pode, ao longo do tempo, se repetir em um conjunto de textos, e se configurar uma tradição discursiva. Segundo 
Kabatek (2006), as tradições discursivas são formas ou estruturas recorrentes em determinadas situações comunicativas com fins pragmáticos específicos. Essas formas não são específicas de uma língua particular, pois são transferidas por grupos culturais, contrariamente a fatos puramente linguísticos, que são transferidos por comunidades linguísticas. Nessa perspectiva, a estruturação do segmento tópico é tratada como tradição no nível individual dos textos.

Nosso objetivo é, portanto, constatar, no contexto do uso social e histórico de um gênero (carta do leitor), especificamente na imprensa do estado do Rio Grande do Norte, se as permanências, modificações, ou exclusões de propriedades formais e funcionais da estruturação do segmento tópico se configuram tradições discursivas, e se são tradições estáveis. Isso posto, analisamos 20 cartas de leitor, organizadas em três grupos, cada um com 5.000 palavras, distribuídos em três intervalos de tempo: segunda metade do século XIX e primeira e segunda metades do século XX.

As cartas de leitor compõem o corpus do projeto Para a História do Português Brasileiro no Rio Grande do Norte (PHPB-RN) ${ }^{1}$, um dos subprojetos vinculados ao PHPB. Do ponto de vista metodológico, trata-se de um trabalho que se insere no âmbito da pesquisa qualitativa. Nesse sentido, não recorremos a recursos e técnicas estatísticas. Ao invés disso, interessa-nos a discussão sobre processos de mudança no nível do texto, o que situa o trabalho também no campo da pesquisa exploratória.

\section{Processos de construção do texto em diacronia}

Desde sua implantação, em 1997, o PHPB deu um grande impulso aos estudos históricos e diacrônicos sobre o português brasileiro (Castilho e Hora 2010; Castilho 2011). Além desse impulso, o projeto também abriu espaço para a descrição diacrônica dos processos linguísticos acionados pela língua, no plano do texto. Esse alargamento trouxe consigo a necessidade de formulação de princípios teóricos específicos, já que, como assinala Mattheier (2011) ainda é pouco reconhecida a mudança no que diz respeito a noções textuais.

Segundo Combettes (2012), a fonética, a sintaxe e mesmo a semântica são disciplinas particulares antes de serem considerados os seus correspondentes históricos, como "fonética histórica", "sintaxe histórica". Assim, pode-se admitir que a problemática diacrônica é muito específica para que as teorias, os conceitos e os métodos que se desenvolveram como estudos sincrônicos não possam ser aplicados tais quais à análise da mudança, mas que seja objeto de uma certa "adaptação". O autor, então, questiona por que isso seria diferente com a linguística textual.

Estamos no direito, então, de nos perguntar por que a linguística textual parece ser tratada de forma diferente das outras disciplinas. Um índice material muito significativo dessa singularidade é, por exemplo, o fato de que dificilmente se pode

\footnotetext{
1 Disponível em: https://sites.google.com/site/corporaphpb/home/corpora-impressos.
} 
citar uma obra que se apresente como uma "linguística textual histórica", como são correntemente citados nos manuais os termos "fonética histórica", "gramática histórica", que fundam um domínio particular. (Combettes 2012: 3) (Tradução nossa $)^{2}$

Segundo o autor, colocar em relação fatos de língua e fatos de organização textual implica considerar que esses dois conjuntos de fenômenos são suscetíveis de serem afetados pela mudança. É inquestionável que o sistema linguístico é afetado pela mudança (e há uma longa história de estudo acerca disso). No entanto, a mudança não é tão evidente para noções textuais, já que essas noções envolvem fatos de outra natureza. "Na medida em que se aceita que a competência do locutor se modifica com o tempo, é preciso considerar como submeter à mudança as noções que a constituem" (Combettes 2012: 5) (Tradução nossa) $)^{3}$. A questão relativa à mudança no domínio das noções textuais, como assinalada por Combettes (2012), ainda carece de aprofundamento.

Não pretendemos, aqui, entrar no mérito e aprofundar essa discussão. No entanto, precisamos apontar um balizamento teórico mínimo sobre a maneira como podemos abordar a questão da diacronia de um processo de construção textual. A nosso ver, um ponto de partida é tentar esclarecer o que se entende por historicidade e por texto. Segundo Kabatek (2005: 151), a existência de diferentes noções de historicidade foi posta por Eugenio Coseriu. Interessa-nos, aqui, de forma particular, a distinção que o autor estabelece entre dois tipos de historicidade: a) a historicidade linguística no sentido restrito (historicidade de uma língua particular); e b) a historicidade como tradições de certos textos ou de certas formas de texto (ou seja, como possibilidade de serem repetidos).

Para Coseriu (1992), uma língua é um produto cultural, histórico e é reconhecida pelos próprios falantes e pelos falantes de outras línguas como língua: a língua alemã, francesa, italiana, por exemplo. Assim, a historicidade da língua é a historicidade do próprio homem como ser histórico. "A língua como língua particular é a história de uma comunidade internalizada nos indivíduos" (Kabatek 2005: 151). Nesse sentido, a língua particular é uma técnica ou um sistema historicamente determinado, que pode ser transmitida de uma pessoa a outra dentro de uma mesma comunidade linguística.

Além da historicidade das línguas como sistemas ou conjunto de sistemas compartilhados entre os indivíduos de uma mesma comunidade, há um segundo tipo de historicidade, a da tradição, ou seja, a possibilidade de repetição de textos como produtos discursivos. Trata-se de uma tradição textual na qual um texto como objeto cultural é criado a partir de certas similaridades ou da identidade parcial com outros textos

2 On est alors en droit de se demander pourquoi la linguistique du texte semble être traitée différemment des autres disciplines. Un indice matériel assez significatif de cette singularité est par exemple le fait que l'on puisse difficilement citer un ouvrage qui se présenterait comme une «linguistique textuelle historique», alors que sont couramment utilisés des manuels de «phonétique historique», de «grammaire historique», qui font le point sur un domaine particulier.

3 Dans la mesure où l'on accepte que la compétence textuelle du locuteur se modifie avec le temps, il faut considérer comme soumises au changement les notions qui la constituent, ne serait-ce qu'en raison de l'évolution des notions mêmes de texte, de textualité et de cohérence. 
Estabilidade e mudança na estruturação de segmentos tópicos em cartas de leitor: contribuição à história do português brasileiro

(Kabatek 2005). Nesse sentido, a historicidade dos textos é distinta da historicidade das línguas.

A macroestrutura dos textos, isto é, a estrutura dos textos como textos, não está relacionada à língua particular. Tampouco textos como Guten Tag! pertencem, como texto, ao nível da língua particular ainda que existam unicamente em uma determinada comunidade linguística. O fato de que, precisamente, Guten Tag! e não outra coisa seja utilizada como forma de saudação é uma tradição textual e não uma tradição linguística particular, ainda que é normal todos os membros da comunidade linguística conhecerem essa expressão. Por esse motivo, eu tampouco diria que, por exemplo, bon matin! não existe em francês, mas diria que esse texto nunca foi formado ou que nunca se converteu em tradição na comunidade linguística francesa. (Coseriu 1992:194) (Tradução nossa) $)^{4}$

Coseriu (2007) também aponta a existência de diferentes concepções de texto. Com base na perspectiva que considera três níveis de conhecimento envolvidos na linguagem (o nível universal ou nível do falar em geral, o nível histórico das línguas, o nível individual), o autor distingue dois conceitos de texto ou duas formas distintas de considerá-lo: o texto-unidade (como fenômeno que pertence ao nível histórico das línguas) e o texto-nível (como fenômeno do nível individual). Consequentemente, o autor também delineia duas formas de linguística do texto, para ele, cientificamente legítimas: a do texto-unidade (gramática textual) e a do texto-nível (linguística textual propriamente dita ou hermenêutica do sentido). Ambas as modalidades não são nem contrárias nem excludentes, mas complementares e integradas, pois se encontram em distintos planos do linguístico: o propriamente idiomático e o individual.

A abordagem do texto-unidade compreende a descrição das categorias e princípios que dão conta das regras de uma língua determinada que atuam na construção do texto. Essas regras ultrapassam o limite da frase ou estão fora dos seus limites. Essas categorias, que determinam relações existentes entre os diversos níveis da língua ou em apenas um nível, são a super ordenação, a subordinação, a coordenação e a substituição.

A abordagem do texto-nível compreende três tarefas: a) indicação da posição dos textos na esfera do linguístico (teoria dos textos), b) construção de uma lista de procedimentos textuais possíveis para a construção do sentido e a delimitação desses procedimentos em relação a outros (linguística do texto geral), e c) descrição e interpretação de um determinado texto, incluído, a exposição da história desse texto (linguística do texto). Nesse sentido, Lamas (2007) defende que essa linguística é três vezes linguística do texto.

4 La macroestructura de los textos, i.e. la estructura de los textos como textos, no está referida a la lengua particular. Tampoco textos como Guten Tag! pertenecen en cuanto textos al nivel de lengua particular, aunque existan únicamente en una determinada comunidad lingüística. El hecho de que precisamente Guten Tag! y no otra cosa se utilice como fórmula de saludo es una tradición textual y no una tradición lingüística particular, aunque lo normal es que todos los miembros de la comunidad lingüística conozcan esa expresión. Por ese motivo, yo tampoco diría que, por ejemplo, Ron matin! no existe en francés, sino que diría que ese texto nunca fue formado o que nunca se convirtió en tradición en la comunidad lingüística francesa. 
Ao relacionarmos essas concepções de texto com as concepções de historicidade, veremos que o texto-unidade, como um nível de estruturação da língua, está relacionado ao primeiro tipo (historicidade das línguas), já o texto-nível, à historicidade dos textos. Com base nisso, podemos desenhar um quadro a partir do qual é possível estudar, de forma coerente, a diacronia dos processos de construção textual. A questão básica é a de que não se pode falar de história e mudança desses processos nos mesmos parâmetros e segundo os mesmos princípios aplicados à história e mudança nos sistemas linguísticos. Como bem assinala Jubran (2010: 264), "a abordagem diacrônica desses processos requer a formulação de princípios teóricos específicos".

A organização tópica, por exemplo, como processo de construção textual não pertence a nenhuma língua em particular, e, consequentemente, não é determinada historicamente por essa língua. Também não é uma característica de um gênero textual em particular (todo texto pertencente a qualquer que seja o gênero apresenta um tópico cuja instauração mobiliza uma certa organização), que pode se tornar como tal uma tradição textual. Segundo Coseriu (2007), há procedimentos comuns para todos os textos que são definidos apenas no nível dos textos como tais, ou seja, são traços universais dos textos através dos quais um texto é um texto e não outra coisa. Nesse sentido, como princípio geral de construção textual, a organização tópica é um fato universal, e, portanto, a-histórico.

Por outro lado, a organização tópica mobiliza certas propriedades formais e funcionais que são determinadas pela situação comunicativa, e, por isso, pertencem ao nível individual dos textos. Nesse sentido, uma determinada propriedade pode, ao longo do tempo, se repetir em um conjunto de textos, e se configurar uma tradição como a que é prevista quando se aborda a historicidade dos textos.

Para dar conta desse tipo de tradição, Kabatek $(2006,2007)$ propõe falar de tradições discursivas, ou seja, formas ou estruturas recorrentes em determinadas situações comunicativas com fins pragmáticos específicos. Essas formas não são específicas de uma língua particular, pois são transferidas por grupos culturais, contrariamente a fatos puramente linguísticos, que são transferidos por comunidades linguísticas. Nessa perspectiva, os procedimentos formais e funcionais mobilizados pela organização tópica podem ser tratados como tradições no nível individual dos textos na medida em que são procedimentos que podem se repetir em um conjunto de textos. Segundo Glessgen (2007: 104), a noção de tradição discursiva se ampara nas relações de repetição e imitação entre os textos. Os textos são grandes repetições e imitações de textos anteriores.

Um enunciado não leva em conta apenas o diasistema. Ele reproduz, ao mesmo tempo, modelos pré-estabelecidos por uma situação comunicativa dada: ao se escrever uma carta, os elementos de abertura e saudação [...] a escolha da variedade do diasistema são definidas antes. [...] Seja para uma carta ou uma conversação, uma poesia ou um artigo científico, os enunciadores reproduzem modelos de outros discursos semelhantes que pertencem ao mesmo gênero textual e usam um vasto 
Estabilidade e mudança na estruturação de segmentos tópicos em cartas de leitor: contribuição à história do português brasileiro

inventário de elementos de língua pré-fabricados. A produção da fala representa, então, mais que um ato de reprodução de formas já existentes do que um ato livre de criação. (Tradução nossa) $)^{5}$

Finalmente, pode-se pensar ainda em mecanismos que são próprios de uma língua que atuam na organização tópica. Pensemos, por exemplo, em um marcador discursivo próprio de uma língua que estabelece a articulação tópica, o português, por exemplo. Trata-se de um recurso gramatical que atua no nível textual da língua, ou seja, um recurso que faz parte das relações constitutivas que caracterizam uma ordem própria do texto. Nesse caso, no entanto, estamos no plano da historicidade linguística e considerando o texto como unidade da língua.

\section{Organização tópica em diacronia: estruturação interna dos Segmentos tópicos mínimos em cartas de leitor}

O tópico discursivo é uma categoria abstrata, primitiva, que se manifesta "na conversação, mediante enunciados formulados pelos interlocutores a respeito de um conjunto de referentes explícitos ou inferíveis, concernentes entre si e em relevância num determinado ponto da mensagem" (Jubran et al. 1992: 361). O tópico, nessa perspectiva, é particularizado por duas propriedades: a centração e a organicidade. A centração abrange a concernência (relação de interdependência que integra os enunciados em um conjunto de referentes explícitos ou inferíveis), a relevância (proeminência desse conjunto de referentes) e a pontualização (localização do mesmo conjunto proeminente em determinado momento do texto) (Jubran et al. 1992, Jubran 2006).

Considerando que, em um texto (seja ele falado ou escrito), podem ser desenvolvidos vários assuntos, e, portanto, vários tópicos, é possível abstrair-se daí uma dada organicidade, expressa na distribuição dos assuntos em quadros tópicos. Para Jubran et al. (1992) e Jubran (2006), a organização tópica pode ser observada em dois níveis: no plano hierárquico e no plano sequencial. No plano hierárquico, as sequências textuais se desdobram em supertópicos e subtópicos, dando origem a quadros tópicos, caracterizados, obrigatoriamente, pela centração num tópico mais abrangente e pela divisão interna em tópicos coconstituintes; e, possivelmente, por subdivisões sucessivas no interior de cada tópico coconstituinte, "de forma que um tópico pode vir a ser ao mesmo tempo supertópico ou subtópico, se mediar uma relação de dependência entre dois níveis não imediatos" (Jubran et al. 1992: 364). No que diz respeito ao plano sequencial, dois processos básicos caracterizam a distribuição de tópicos na linearidade discursiva: a continuidade e a descontinuidade. A continuidade se caracteriza por uma relação de

5 Un énoncé ne tient pas simplement compte du diasystème. Il reproduit en même temps des modèles préétablis pour une situation communicative donnée : s'il s'agit d'écrire une lettre officielle, les éléments d'ouverture et de salutation [...] voire le choix de la variété diasystématique sont définis d'avance. [...] Pour une lettre ou une conversation d'achat comme pour une poésie ou un texte scientifique, les énonciateurs reproduisent le modèle d'autres discours semblables appartenant au même genre textuel et ils puisent dans un vaste inventaire d'éléments de langue préfabriqués. La production de la parole représente alors plus un acte de reproduction de formes déjà existantes qu'un acte de libre création. 
adjacência entre dois tópicos, com abertura de um tópico subsequente somente quando o anterior é esgotado. A descontinuidade se caracteriza por uma perturbação da sequencialidade linear, causada ou por uma suspensão definitiva de um tópico, ou pela cisão do tópico, que passa a se apresentar em partes descontínuas.

Em termos analíticos, identificam-se e delimitam-se, no texto, os segmentos tópi$\cos$ (SegTs), que são as unidades textuais concretas que atualizam as propriedades do tópico. O segmento tópico (SegT) é, portanto, a unidade textual que, em termos de centração, revela concernência e relevância no conjunto de seus elementos e se localiza num determinado ponto do texto.

Dessa forma, enquanto o tópico discursivo é uma categoria analítica abstrata, o SegT é a unidade textual que preenche as propriedades dessa categoria. Os SegTs mínimos são, portanto, unidades textuais que, em termos de centração, revelam concernência e relevância no conjunto de seus elementos e se localiza num determinado ponto do evento comunicativo, submetida à organização tópica negociada pelos interlocutores. O SegT mínimo, em outras palavras, constitui cada conjunto de enunciados tematicamente centrados.

Para ilustrar, tomamos um exemplo hipotético de um texto cujo tópico central ou supertópico é ocupações com os filhos. Esse tópico apresenta, em um primeiro nível da organização tópica hierárquica, dois subtópicos: problemas de João e novidades de Ana. Cada um desses tópicos apresenta ainda um segundo nível de desdobramento: o tópico problemas de João se desdobra em problemas de João na faculdade (atualizado no SegT 1) e problemas de João no trabalho (atualizado no SegT 2); o tópico novidades de Ana se desdobra em o carro novo de Ana (atualizado no SegT 3) e o casamento de Ana (atualizado no SegT 4). O quadro 01 resume a organização hierárquica desse texto hipotético.

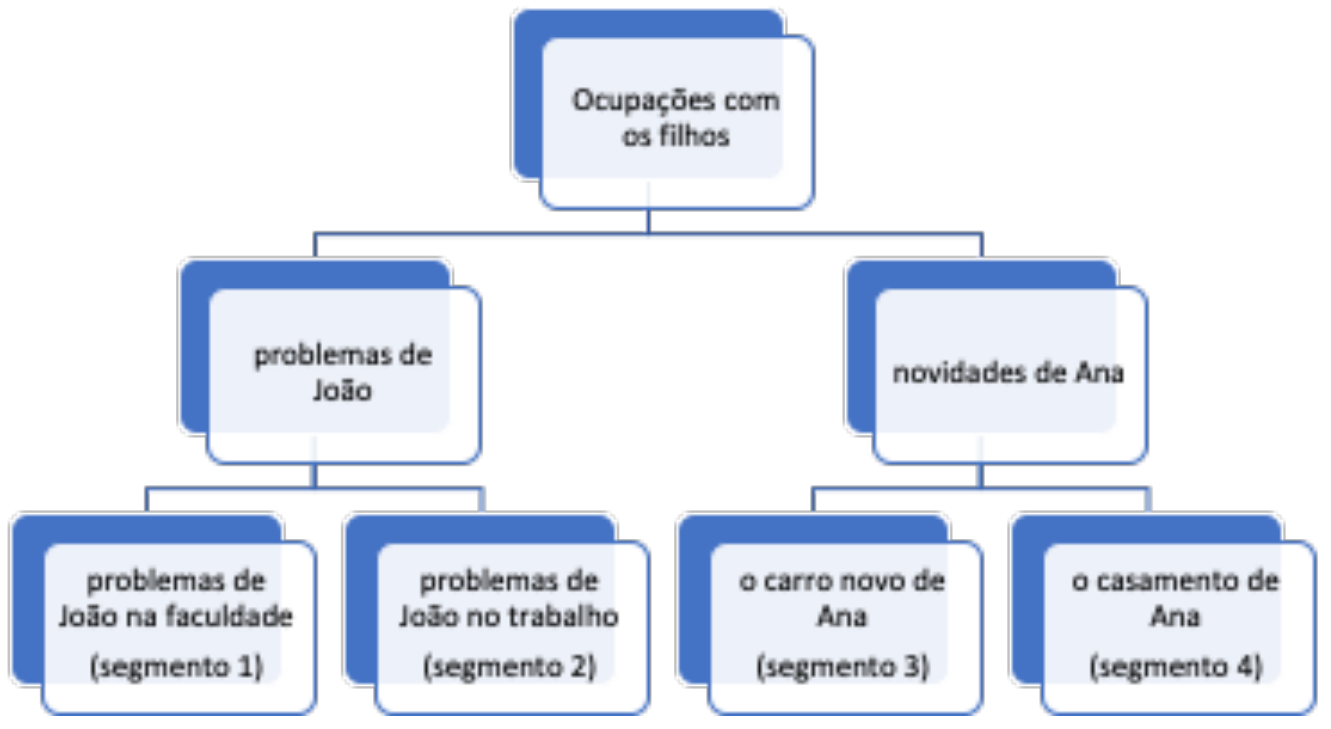

Quadro 01: organização tópica hierárquica de texto hipotético. Fonte: Penhavel e Diniz (2014) - adaptado 
No que diz respeito a princípios gerais de estruturação tópica, a estruturação intertópica (a do nível acima dos SegTs mínimos) conta com noções importantes já desenvolvidas, que permitem explicar grande parte dos princípios estruturadores desse plano da organização tópica (p. ex. Jubran et al. 1992; Jubran, 2006). O conjunto formado por um supertópico e seus respectivos subtópicos constitui um quadro tópico. As relações se dão, portanto, entre os supertópicos que formam os diferentes quadros tópicos e entre os subtópicos no interior dos quadros tópicos. É esse princípio geral que estrutura a organização intertópica.

Quanto à estruturação intratópica, trata-se de uma questão que ainda carece de mais desenvolvimento. Um trabalho pioneiro nesse sentido é o de Penhavel (2010). Tomando como base o gênero Relato de Opinião, o autor defende a existência de uma regra geral de estruturação intratópica fundada na relação posição-suporte. A partir disso, o autor e outros colaboradores têm demonstrado a recorrência dessa regra em outros gêneros, assim como a possibilidade de existência de outras.

Especificamente a cartas de leitor, Penhavel e Diniz (2014: 25) demonstram que a estruturação interna dos SegTs mínimos está vinculada ao propósito central do gênero: "discorrer sobre determinada situação, exposta como sendo um problema, e solicitar que alguma medida seja tomada no que se refere a tal situação". Trata-se, nesse sentido, de uma unidade que envolve a construção de uma situação-problema, e, por essa razão, compreende quatro subunidades: abertura, explicação, avaliação e interpelação. Essa forma de estruturação constitui uma regra geral de estruturação intratópica prototípica. É possível, no entanto, haver cartas que não apresentam todas as subunidades: "a regra não implica que as quatro unidades ocorram obrigatoriamente no SegT, podendo ocorrer apenas três, duas ou uma dessas unidades (na ocorrência de apenas uma unidade, esta, naturalmente, não pode ser a Abertura devendo ser qualquer uma das outras três)" (Penhavel e Diniz 2014: 26).

Há, ainda, segundo Penhavel e Diniz (2014: 31), uma segunda regra possível baseada no princípio de que os segmentos "são estruturados internamente com base em uma alternância entre grupos de enunciados que constroem referências centrais e grupos de enunciados que constroem referências subsidiárias em relação à ideia nuclear". Essa segunda regra está, nesse sentido, fundada na relação posição-suporte, que são as duas subunidades a partir das quais se estrutura o segmento.

Vejamos a carta $01^{6}$. O autor inicia o segmento, apresentando o tópico: prestação de contas do prefeito ("deixa de | fazer a necessária prestação de | contas de importancia recebida | do Tesouro Estadual, quando | no exercicio de Prefeito do $\mathrm{Mu}$ - | nicipio de São Rafael"). Os enunciados que se seguem constituem o desenvolvimento desse tópico, que é tratado como uma situação-problema. Nesse caso, a estruturação interna do segmento obedece à primeira regra, e apresenta as quatro subunidades: abertura, explicação, avaliação e interpelação. Já a carta 02 apresenta como tópico natureza religiosa da yoga. A estrutura do segmento segue a segunda regra: uma unidade de posição e

6 Para a análise, não consideramos local e data, saudação inicial e despedidas, porque são componentes da estrutura retórica da carta não relacionados à categoria do tópico. 
outra unidade de suporte. A posição é a de que a yoga não é uma religião. Na unidade de suporte, figuram as evidências para essa posição.

Reproduzimos, a seguir, os dois textos de modo que essa subdivisão seja visualizada.

Carta 01

Natal, 8 de maio de 1957 || Ilmo Snr. || Redator Chefe de "A Tribuna | do Norte || NESTA.

abertura

|| Tendo o Jornal do Comér- | cio desta Capital, em edição de 7 do corrente mês, sob o títu- | lo "Notas de um reporterpo- | lítico", procurado demonstrar | perante a opinião pública dês- | te Estado, de que deixa de | fazer a necessária prestação de | contas de importancia recebida | do Tesouro Estadual, quando | no exercicio de Prefeito do Mu- | nicipio de São Rafael, venho | pela presente, solicitar do ilus- | tre Redator, transcrever nas | colunas dêsse conceituado ma- | tutino, como formal desmenti- | do, os esclarecimentos abaixos:

explicação

|| Efetivamente, ao assumir o | cargo de Prefeito de São Ra- | fael, em principios do mês de | junho de 1951, recebi do Tesou- | ro Estadual, a importancia de | Cr\$ 15.000, 00 (quinze mil cru- | zeiros), para ocorrer ao paga- | mento das despesas com a cons- | trução do cêrco do perímetro | urbano da Cidade de São Ra- | fael. ||

avaliação

A mencionada importancia, | foi totalmente empregada no | referido serviço, conforme com- | provantes devidamente auten- | ticados e escriturados ás fls. | 24 do livro caixa numero 2, da- | quéla municipalidade, justamen- | te no momento em que fazia a | transmissão do cargo de Prefei- | to ao meu ilustre sucessor, Ca- | pitãoHeraclito Pinheiro, cu- | jo testemunho poderei invocar $\mid$ a qualquer momento. interpelação

|| Não tenho, portanto, moti- | vos para temer qualquer de- | vassa em minha curta vida pu- | blica, o que talvez não acon- | teça com o meu gratuito des- | conhecido caluniador, que, não | tendo coragem de me atacar | pessoalmente, procura guarida | nas colunas de um jornal para | atraçalhar a honra de um cida- | dão que jamais lançou mão de | expedientes escusos em seu | proveito ou de quem quer que | sêja. ||

Agradecendo, de antemão, a | atenção que vier dispensar ao | assunto, valho-me da oportuni- | dade para apresentar-lhe os | meus protestos de elevada es- | tima e devida consideração. || Cordialmente | Pio Marinheiro de Sousa”

Carta 02

YOGA || Senhor Editor, \|

posição

Sou leitor assíduo deste | Jornal corajoso e imparcial | na notícia de nosso Estado. || Quero através desta | fazer comentários a respeito | das declarações prestadas | pela Professora de Psicolo- | gia, Senhora Maria de Fá- | timaCortez, ora descritas no comentário sobre os | Mercenários da fé, com- | parando grosseiramente os | praticantes de YOGA como seita religiosa | ou "coisa" parecida. || 
suporte

Queria deixar claro que | YOGA não é religião e | muito menos seita religio- | as. Yoga é sim uma filoso- | fia milenar que teve sua | origem no século III A.C. E que é praticada em todos | os países do mundo, seja | capitalista ou socialista, | seus praticantes de di- | versas religiões e que tem | sua formação hoje asse- | gurada pelas Universidades | onde são preparados os | futuros instrutores desta filosofia. É comum nas nossas práticas encontrar | adeptos de várias religiões | entre elas os católicos, pa- |dres, freiras, pastores e protestantes. Gostaria muito que o $\mid$ meu esclarecimento fosse | aceito no espaço de cartas | destinadas aos leitores. || Carlos Alberto Honorato de | Carvalho || Rua Pte Pamplona, 1834 || Candelária

Do ponto de vista diacrônico, defendemos que cada uma dessas regras de estruturação pode, ao longo do tempo, se repetir em um conjunto de textos relacionados a um gênero, carta pessoal, no nosso caso, e se configurar uma tradição discursiva (Kabatek 2006). Cada carta do corpus foi analisada individualmente, com base no critério da centração, para identificação e segmentação dos tópicos constituintes. Observamos, então, a constituição interna de cada SegT mínimo que compõe as cartas, ou seja, a organização intratópica.

A análise apontou a convergência do propósito comunicativo das cartas, o de discorrer sobre uma situação-problema, e da primeira regra prototípica de estruturação intratópica. No entanto, essa convergência se desfaz, quando se considera a mobilização das subunidades. No que diz às subunidades mobilizadas, observamos algumas repetições a partir das quais se configuram cinco padrões, que designamos com as letras de A a E.

No padrão A, a estruturação interna do segmento apresenta as quatro subunidades (abertura, explicação, avaliação e interpelação). No padrão B, a estruturação interna do segmento apresenta apenas duas das quatro subunidades (abertura e explicação). No C, a estruturação interna do segmento apresenta apenas duas das quatro subunidades (abertura e avaliação). Na D, a estruturação interna do segmento apresenta apenas duas das quatro subunidades (abertura e interpelação). Finalmente, no padrão E, a estruturação interna do segmento apresenta uma das quatro subunidades (abertura).

A segunda regra (fundada na relação de suporte de posição, que são as duas subunidades a partir das quais o segmento é estruturado) também é mobilizada, o que configura o padrão que designamos como F. Além desses padrões, observamos que algumas poucas cartas não se estruturam conforme as duas regras que prevíamos. A esse padrão designamos como $\mathrm{G}$, e o tratamos como um padrão default. A tabela 01 sintetiza esses resultados, mostrando o padrão relacionado ao período em que as cartas foram escritas: segunda metade do século XIX (XIX2), primeira metade do século XX (XX1) e segunda metade do século XX (XX2). 
Tabela 01: Padrões de regras de estruturação intratópica.

\begin{tabular}{|l|c|c|c|c|c|c|c|}
\hline Período & \multicolumn{7}{|c|}{ Padrão } \\
\hline & $A$ & $B$ & $C$ & $D$ & $E$ & $F$ & $G$ \\
\hline $\mathrm{XIX} 2$ & & & & & & & \\
\hline $\mathrm{XX} 1$ & & & & & & & \\
\hline $\mathrm{XX} 2$ & & & & & & & \\
\hline
\end{tabular}

Fonte: elaboração do autor

Essa síntese permite pensar que esse conjunto de cartas de leitor mobiliza propriedades formais comuns vinculadas a efeitos pragmáticos: regras de estruturação intratópica vinculadas ao propósito comunicativo do gênero. Em outras palavras, essas propriedades criam padrões aos quais pertence esse conjunto específico de textos. No contexto do uso social e histórico desse conjunto de textos, esses padrões não são estáveis: ocorrem repetições ou exclusões. A ligação de um texto com outros, aqui de forma particular, de uma carta com outras, as relações de retomada e repetição de regras de estruturação intratópica constituem, portanto, a nosso ver, uma tradição. No caso das cartas em questão, trata-se de uma tradição que sofre mudanças ao longo tempo. Há padrões que se repetem, outros que desaparecem, e outros que se inserem, o que se converte em outra realidade totalmente diferente da inicial. No período XIX2, as cartas mobilizam apenas duas subunidades da regra prototípica (padrão $\mathrm{B}$ e C) e o padrão default, que, aliás, se repete nos demais períodos. No período XX1, os padrões B e G se repetem, o padrão C é excluído, e o padrão A é inserido. No período XX2, todos os padrões se repetem.

Com base nesses dados, podemos afirmar que as regras de estruturação intratópica não pertencem à realização tradicional do sistema de uma língua, não é uma característica da língua portuguesa em particular. Trata-se de um procedimento, de fato, realizado segundo as regras do português, mas que pertence a uma certa tradição de falar, que pode ser repetida e acrescida de um valor que resulta em seu caráter de signo autônomo e na sua repetibilidade. Estamos falando, assim, de um fenômeno da "segunda historicidade", para a qual, segundo Kabatek (2015: 198) o conceito de tradição é, sem dúvida, muito apropriado: "essa repetibilidade pode ser tanto de expressões curtas como de expressões complexas e longas. Ela pode ser integral ou parcial, e se reportar tanto a elementos formais (fórmulas ou formas textuais) como a elementos de conteúdo (topoï, etc)" 7 .

\section{Considerações finais}

Nosso ponto de partida para este trabalho foi a proposta de análise diacrônica de fenômenos textuais desenvolvida no contexto do PHPB. Ao discutirmos essa proposta, defendemos que o estudo da mudança no que diz respeito a fatos de natureza textual requer um aparato teórico específico. O pressuposto segundo o qual uma concorrência

\footnotetext{
7 Citação original em francês (tradução nossa).
} 
de formas de valor igual ou semelhante pode acarretar a substituição de uma por outra ao longo do tempo não se aplica à análise de processos de construção textual. Por outro lado, a partir da proposta de Coseriu sobre os níveis da linguagem, entendemos que um processo de construção textual como tal não pertence a nenhuma língua. Constitui um traço universal dos textos através do qual um texto é um texto e não outra coisa. Nesse sentido, é imutável e atemporal. Não se pode, portanto, falar em mudança. Outros processos de construção podem, ao longo do tempo, se repetir em um conjunto de textos relacionados a um gênero, e se configurar como uma tradição discursiva, e apenas nesse sentido podem ser afetados pela mudança. As regras de estruturação intratópica foram tomadas como um caso desse tipo de processo.

Realizamos, assim, o exercício de analisar um conjunto de textos pertencentes ao gênero carta do leitor, publicadas em jornais do estado do Rio Grand do Norte Brasil, nos séculos XIX e XX, para constatar se as permanências, modificações, ou exclusões de regras de estruturação intratópica configuram tradições discursivas, e se são tradições estáveis. A análise nos permitiu chegar às seguintes conclusões:

a) a estruturação intratópica não deve ser entendida como um processo de construção textual que pertence a uma língua em particular, assim como não deve ser vista como uma característica de um gênero textual em particular, pois todo gênero apresenta uma organização tópica;

b) considerando a distinção entre historicidade da língua e historicidade dos textos e entre texto-unidade e texto-nível, o estudo diacrônico da estruturação intratópica se situa no nível da historicidade dos textos, como um fenômeno que pertence à construção do texto, concebido como nível individual da linguagem;

c) a relação de uma carta de leitor com outras no que diz respeito à retomada e repetição de determinadas regras de estruturação intratópica configuram tradições discursivas;

d) com base na relação de retomada e repetição de regras de estruturação intratópica, foram identificadas tradições discursivas instáveis;

e) embora não tenha sido foco da análise, é possível inferir que as retomadas e repetições de regras de estruturação intratópica que se configuram como tradições discursivas estão relacionadas às alterações no uso social do gênero;

f) as regras de estruturação intratópica, embora mobilizem mecanismos próprios da língua portuguesa, não pertencem à realização tradicional do sistema e não é uma característica dessa língua, mas a uma certa tradição de falar.

Essas conclusões são, em certa medida, pontuais, porque estão relacionadas a um único processo de construção textual, de um conjunto específico de textos vinculados a um gênero (carta do leitor), de apenas um estado (Rio Grande do Norte). No entanto, ao serem comparadas com conclusões de trabalhos semelhantes sobre outros objetos, outros textos e outras regiões do país, teremos a possibilidade de caminhar rumo ao 
propósito do PHPB que é o de conhecer a realidade linguística brasileira do ponto de vista da sua história. Além disso, apontamos como pertinente a aplicação da noção de tradição discursiva ao tratamento diacrônico de fenômenos textuais.

\section{BIBLIOGRAFIA}

CASTILHO, A. T.; HORA, D. da (Orgs.) (2010): História do Português Brasileiro: versão preliminar. João Pessoa: UFPB.

CASTILHO, A. de (2011): "História do português de São Paulo". Filologia e Linguística Portuguesa. n. 13(1): 57-61.

COMBETTES, Bernand (2012) : "Linquistique textuelle et diachronie". 30 Congrès Mondial de Linguistique Française, SHS Web of Conferences, Vol. 1, 3-10.

COSERIU, Eugenio (2002): Competencia linguística: elementos de la teoría del hablar. Madrid: Gredos.

(2007) : Lingüistica del texto. Introducción a la hermenéutica del sentido, édition et annotation d'Óscar Loureda Lamas. Madrid: Arco/Libros.

GLESSGEN, M-D. (2007): Linguistique romane, Paris: Armand Colin.

JUBRAN, C.C.A.S. et al. (1992): "Organização tópica da conversação", ILARI, R. (Org). Gramática do português falado, v. II. Campinas/SP: UNICAMP; São Paulo: FAPESP, 322-384.

(2006): "Perspectiva textual-interativa", JUBRAN, C.C.A.S. e KOCH, I. G. V. (Orgs.). Gramática do português culto falado no Brasil - a construção do texto falado. Campinas: Editora da UNICAMP, vol. I., 27-36.

(2010): "Abordagem diacrônica dos processos constitutivos do texto - Introdução", CASTILHO, A. T. e HORA, D. da (Orgs.). História do Português Brasileiro: versão preliminar. João Pessoa: UFPB, 268-273.

KABATEK, J. (2005): "A propos de l'historicité des textes", MURGUÍA, A. Sens et références. Tübingen: Mélanges Georges Kleiber, 149-157.

(2006): "Tradições discursivas e mudança linguística", LOBO, T. et al (Orgs). Para a história do português brasileiro. Salvador: EDUFBA, Vol. 6., 513-554. (2007): "Las tradiciones discursivas entre conservación y innovación". Rivista di filologia e letterature ispaniche, Vol.10, 331-345.

MATTHEIER, K. J. (2011): "Aspectos de uma teoria da mudança linguística". Revista de Letras, Vol. 30, 1/4, 171-183.

PENHAVEL, E. (2010): Marcadores discursivos e articulação tópica, Campinas-SP: [s.n.].

PENHAVEL, E.; DINIZ, T.C.G. (2014): “O processo de estruturação interna de segmentos tópicos mínimos em cartas de leitores mineiras do início do século XXI”. Revista (Con) Textos Linguísticos, Vol.8, n. 11: 21-38.

PINHEIRO, C. L. (2005): Estratégias textuais-interativas: a articulação tópica. Maceió: EDUFAL. 
Estabilidade e mudança na estruturação de segmentos tópicos em cartas de leitor: contribuição à história do português brasileiro

\section{PERFIL ACADÉMICO-PROFESIONAL}

Professor de linguística na Universidade Federal do Rio Grande do Norte (UFRN), em Natal, Brasil. Tem publicado diversos artigos, no Brasil e no exterior, e orienta dissertações e teses no domínio dos estudos do texto/discurso. Suas pesquisas abordam a estrutura e a organização do texto/discurso. Também se interessa pela história das ideias linguísticas.

Fecha de recepción: 07/04/2020

Fecha de aceptación: 26/05/2020 